Research Article

\title{
Stress Distribution on the Fe Based Amorphous Toroidal Transducer Core
}

\author{
Mustafa Göktepe \\ Department of Physics, Faculty of Science and Literature, Balikesir University, \\ 10145 Balikesir, Turkey
}

Correspondence should be addressed to Mustafa Göktepe; goktepe4@gmail.com

Received 4 May 2013; Revised 2 January 2014; Accepted 9 January 2014; Published 25 February 2014

Academic Editor: Achim Trampert

Copyright (C) 2014 Mustafa Göktepe. This is an open access article distributed under the Creative Commons Attribution License, which permits unrestricted use, distribution, and reproduction in any medium, provided the original work is properly cited.

\begin{abstract}
The basic principles of sensors are the transmission of energy from one system to another. In general, an electrical signal is produced by the change of a physical property induced by the applied change of a second parameter. In the case of magnetic transducers either the property or the parameter would have a magnetic context. For example, in magnetoelastic toroidal transducers, the induced changes of a physical property, that is, the variation of permeability caused by the applied external force are used to produce a variation in output signal. The linearity, magnitude, sensitivity, and repeatability of the relationship between the output signal of the transducer and the physical property define the quality of the transducer.
\end{abstract}

\section{Introduction}

Transducers are devices which convert physical energies into electrical signals or vice versa. Magnetoelastic effects form the basis of a number of transducer and sensor designs for both specialised applications and for more general applications involving measurement of force and strain [1].

The magnetoelastic effect known as magnetostriction causes a magnetic material to distort when a magnetic field is applied. The iron rich metallic glasses have sizeable magnetostriction constants, and the coupling of magnetic and mechanical parameters can be enhanced by annealing the amorphous ribbon appropriately in an external magnetic field.

The converse of magnetostriction is made use of in force or strain sensors. When the amorphous ribbon is stretched or bent, the size and the shape of the $B-H$ loop are altered. Thus the tension applied to a straight piece of amorphous ribbon can be detected inductively with the help of a small coil of wire wrapped around the strip. Among the advantages of amorphous alloys for such applications are their exceptionally high tensile strengths and the fact that they retain elasticity when stretched close to their ultimate strengths. The differences in transducers using the inverse effect are the magnetisation conditions (dc, ac, or no applied field) and the material configurations (strip, toroid, or wire) [2].

If we consider the principles of the construction and design of magnetoelastic transducers, three basic systems can be described based on the Villari effect [3]:

(i) systems with a predefined magnetic flux path where the inductance or permeability is changed by mechanical loading in one direction (one-dimensional) such as those described by Mohri and Korekoda [4], Mohri and Sudoh [5], and Meydan [2];

(ii) systems having flux configurations which change in two directions but in one plane due to loading (twodimensional);

(iii) systems where the flux configuration is spatially and vectorially changed by the applied load (two- or threedimensional).

The combination of high yield stress and the magnetoelastic properties of amorphous ribbon materials make them suitable for magnetic sensor and transducer applications. Amorphous ribbon toroidal transducers were investigated by Mohri et al. [6,7] and Meydan et al. [8-10] for displacement, force, and pressure measurement purposes. In addition to this, the influence of bending stress on domain motion 
and flux distribution in amorphous material based toroidal transducers [11] and the stress distribution within amorphous toroidal transducer cores [12] have also been studied by several researchers. In this paper, measurement of stress distribution on the Fe based amorphous toroidal transducer cores will be discussed.

\section{Experimental Setup}

When a displacement or force is applied to the transducer, a bending stress occurs within the amorphous toroidal core. A displacement applying mechanism was constructed in order to apply displacements on the toroidal core with $\pm 0.5 \mathrm{~mm}$ resolution.

The toroidal transducer core was bonded to the holders using double sided tape at the $0^{\circ}$ and $180^{\circ}$ positions of the cores. A ruler with $0.5 \mathrm{~mm}$ divisions was fixed to the base, thereby allowing a display $(0.5 \mathrm{~mm}$ resolution $)$ of the applied displacement.

Once the strain gauge has been installed, the cement cured, and the lead wires connected, there are several quick tests which can be made to ensure that the gauge will function properly. First the gauge resistance needs to be checked. If an open circuit is detected yet all the soldered connections are conductive, then the gauge may have been damaged during bonding and of course, it is useless. If the value of the gauge resistance is noticeably different from the manufacturer's specifications, the gauge should be regarded with extreme suspicion and for this too indicates probable gauge damage during handling or bonding (assuming that ohm meter used is accurate).

Next, the resistance between the strain gauge filament and the metal surface, to which the gauge is attached, should be measured. A thoroughly dried or cured gauge will show a resistance of $1000 \mathrm{M} \Omega$ or higher, although much lower resistance can be tolerated without a too serious consequence. A minimum of $50 \mathrm{M} \Omega$ is considered necessary for accurate, stable functioning of the gauge. Attempts should not be made to use gauges with resistance to ground of less than $10 \mathrm{M} \Omega$, except for dynamic strain indication [13].

The strain gauges were bonded to the inner and outer surfaces of the toroidal transducer core, as shown in Figure 1. Basic bonding procedure was followed as mentioned above. Stress measurements could then be carried out with the use of a bridge.

2.1. Stress Measurement System. It is possible to measure induced stress on the toroidal core using strain gauges and the bridge system. In this investigation, $2 \mathrm{~mm}$ gauge length and $120.0 \Omega \pm 0.2 \Omega$ foil type strain gauges with gauge factor $2.00 \pm 0.26$ were used $[14,15]$. A Philips PR9307 Carrier Frequency Strain Gauge Bridge with 95\% accuracy was used for stress measurements on the surface of the sample [16]. A dummy gauge was used for compensation purpose and was permanently connected to bridge. The active gauges were connected to the bridge and the internal resistance of the bridge was initially balanced for each measurement.

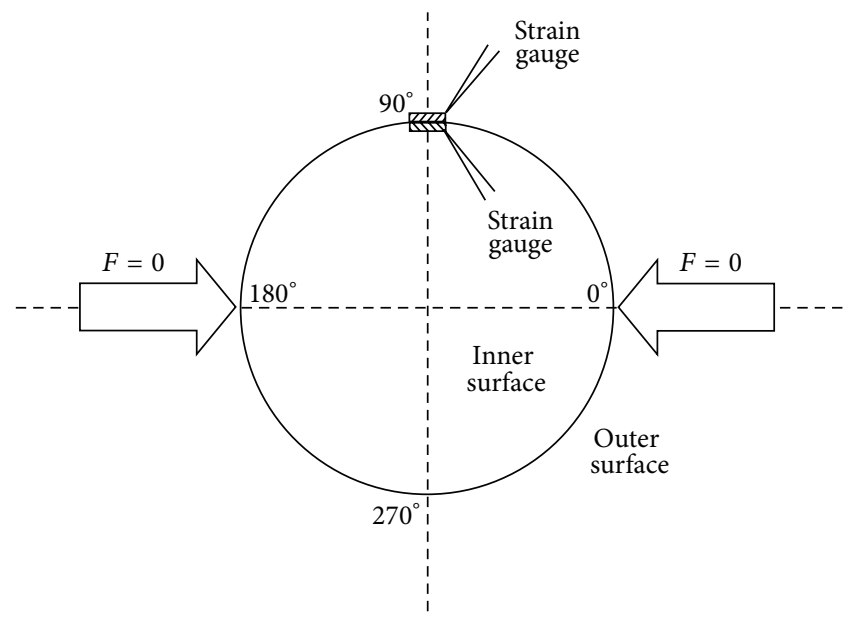

FIgURE 1: Position of the strain gauges on the inner surface and outer surface of the toroid and direction of the applied forces.

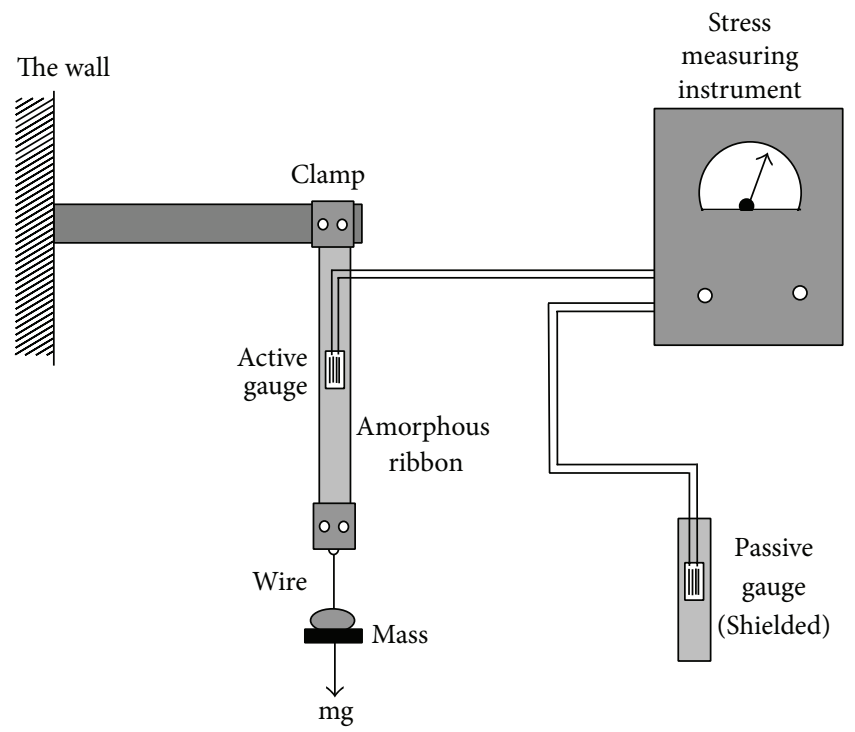

FIGURE 2: Block diagram of the calibration system of the bridge (the other two arms of the bridge are internal to the measuring instrument).

The calibration factor was determined with the use of the bridge. As illustrated in Figure 2 the sample was suspended vertically and weights ranging from $0.450 \mathrm{~kg}$ to $1.800 \mathrm{~kg}$ were hung from its other end.

The bridge was initially balanced then the output signal from the bridge was recorded with the galvanometer; this procedure was carried out for each weight individually, and the strain corresponding to each weight was calculated using the following equation:

$$
\text { Strain }=\frac{\mathrm{OPB}}{\mathrm{FC}} \times C \times \mathrm{RF}
$$

where OPB is output from the bridge, FC is the full-scale value of the bridge, $C$ is a constant, and RF is the range factor for the bridge which are obtained from the manual of Philips 
TABLE 1: Selected properties of Fe based amorphous ribbon, which were used to construct toroidal transducer core.

\begin{tabular}{lc}
\hline Properties & Specifications \\
\hline Alloy & Fe base \\
Chemical formula & $\mathrm{Fe}_{81} \mathrm{~B}_{13.5} \mathrm{Si}_{3.5} \mathrm{C}_{2}$ \\
Elastic modulus & $58.00 \mathrm{MPa}$ \\
Thickness of ribbon & $30.00 \mu \mathrm{m}$ \\
Width of ribbon & $13.00 \mathrm{~mm}$ \\
Thickness of toroidal core & $0.50 \mathrm{~mm}$ \\
Diameter of toroidal core & $30.00 \mathrm{~mm}$ \\
Strain gauge size & $2.00 \mathrm{~mm}$ \\
\hline
\end{tabular}

PR9307 Carrier Frequency Bridge [16]. Finally, induced stress on the sample can be obtained from the following equation:

$$
\sigma_{\text {measured }}=E \times \text { Strain }(\mathrm{MPa})
$$

where $\sigma_{\text {measured }}$ is the measured stress and $E$ is the elastic modules (Young's modulus) of the sample which is obtained from Table 1.

The stress caused by each weight was calculated using the following equation:

$$
\sigma_{\text {calculated }}=\frac{m \times g}{A}(\mathrm{MPa})
$$

where $\sigma_{\text {calculated }}$ is the stress, $m$ is the mass, $g$ is the acceleration due to gravity $\left(9.81 \mathrm{~m} / \mathrm{s}^{2}\right)$, and $A$ is the cross-sectional area of the sample which is equal to the thickness of the sample multiplied by its width $\left(6.35 \times 10^{-7} \mathrm{~m}^{2}\right)$. This procedure was carried out five times to assess the repeatability. In all the sets of readings taken, the largest variation in the values obtained was $\pm 0.26 \mathrm{MPa}$ with a $99 \%$ confidence level.

During the determination of stress, the masses were measured using an electronic scale which has a resolution of $0.1 \mathrm{~g}$. The cross-sectional area, $A$, of the sample was attained through using Vernier callipers to obtain the width and a micrometer to obtain the thickness of the sample. The Vernier readings taken were within $0.02 \mathrm{~mm}$ resolution and the micrometer readings had a resolution of $0.001 \mathrm{~mm}$. In total, the error in the stress value was $\pm 0.26 \mathrm{MPa}$ with a $99 \%$ confidence level.

A graph of calculated stress versus measured stress is shown in Figure 3. The calibration factor was calculated from the gradient of the linear curve and was obtained as $2.745 \pm 0.26$ (99\% confidence level). The characteristics of the $2 \mathrm{~mm}$ strain gauge were nonlinear up to $5 \mathrm{MPa}$ stress values, which corresponded to about $0.300 \mathrm{~kg}$ mass. Due to this, the first reading was taken using the $0.455 \mathrm{~kg}$ mass in this region; the nonlinearity of the strain gauge does not affect the results. Since the minimum measured stress was about $\pm 8.70 \mathrm{MPa}$, effects due to nonlinearity were not taken into consideration.

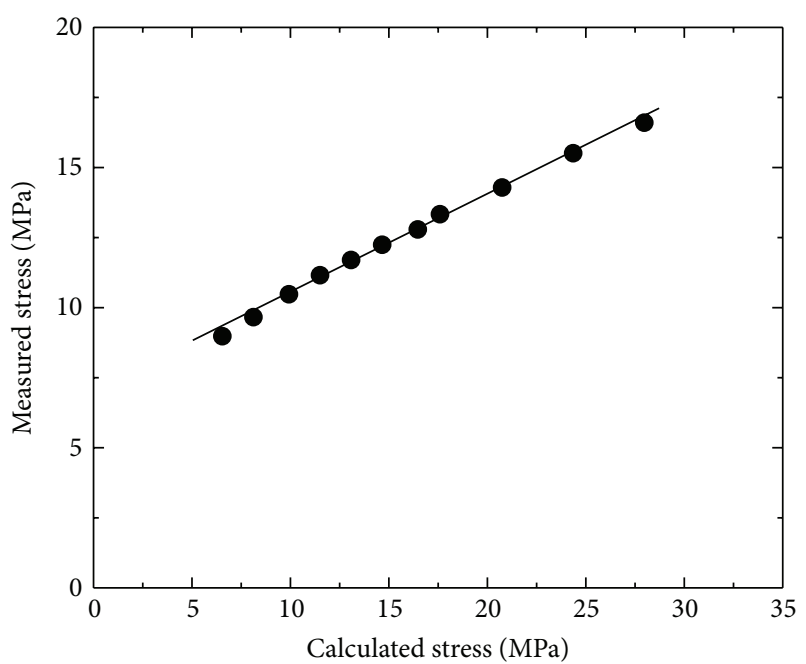

FIGURE 3: Calibration curve of the bridge.

\section{Results and Discussions}

3.1. Calculation of Stress in the Toroidal Transducer Core. It was very important to make sure that the measured stress values were correct. The numerical calculation of stress in the toroidal transducer core was done to try and compare results with those attained through experimental work.

A toroidal transducer core was fixed to the displacement mechanism and displaced. Deformed patterns of the core were transferred directly to paper by using a pencil. The radius of curvature of the bent region of the core was measured and the associated stress was calculated using the following equation:

$$
\sigma_{d}=\frac{E}{\left(1-v^{2}\right) \gamma_{d}} \times \frac{W}{4}(\mathrm{MPa})
$$

where $\sigma_{d}$ is the calculated stress in the core, $E$ is the elastic modulus of the sample, $v$ is Poison's ratio for the sample material (0.3) [12], $\gamma$ is the radius of the curvature of the bent region, and $W$ is the thickness of the toroidal core $(0.5 \mathrm{~mm})$. Before commencing with the measurements the bridge had to be balanced for $0 \mathrm{~mm}$ displacement; hence initially a zero stress condition existed. The toroid was then displaced and stress measurements were taken for increasing displacements, from $0 \mathrm{~mm}$ to $25 \mathrm{~mm}$. Because of this the calculated stress needed to be calibrated to zero for $0 \mathrm{~mm}$ displacement condition; the value of the calculated stress at the $0 \mathrm{~mm}$ displacement condition, $\sigma_{o}$, was subtracted from each of the calculated stress values $\sigma_{d}$ to give the real value of calculated stress at the $90^{\circ}$ position. A graph of stress versus displacement is shown in Figure 4.

Calculated stress values were less than $2.2 \%$ of the measured stress values for $25 \mathrm{~mm}$ displacement. The possible reason of this could be either measurement error of the diameter of curvature at bent region or measurement error of the induced stress. 


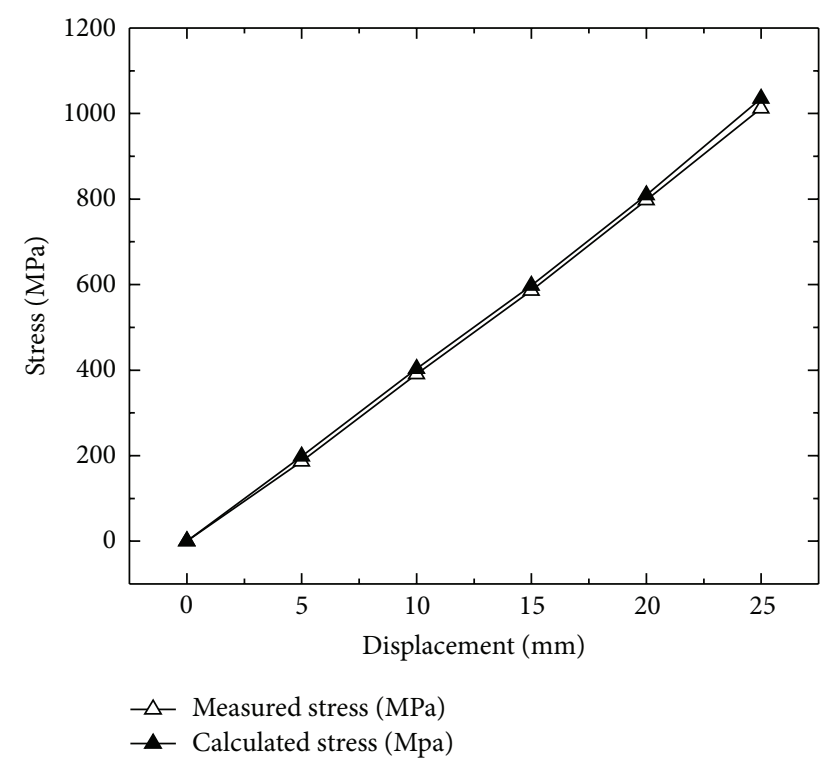

FIGURE 4: Comparison of the measured stress with calculated stress on the outer surface of the toroidal transducer core.

\subsection{Measurements of Stress Distribution on the Toroidal} Cores. Amorphous materials are suitable for magnetic transducer applications, because of their unique magnetoelastic and magnetostriction properties. The Fe based amorphous material with different metal-metalloid composition [11] was used to construct toroidal transducer core. Variation in composition is used to provide a wide variety of magnetic and mechanical properties.

The Fe based amorphous material was produced by Allied Signal Inc. using the drum quenching technique; the ribbon has a thickness of $30 \mu \mathrm{m}$. The multiwrap amorphous toroidal transducer core was constructed with $30 \mathrm{~mm}$ inner diameter, $0.5 \mathrm{~mm}$ thickness, and $13 \mathrm{~mm}$ width. Stress measurements were carried out using $2 \mathrm{~mm}$ long, $120 \Omega$ foil type strain gauges, and an ac strain gauge bridge. The bridge was initially calibrated before the measurements. Strain gauges were bonded on to the inner and outer surfaces of the samples using two component epoxy cement and were cured at room temperature for 10 hours.

In order to get accurate readings from the strain gauges, the surface was cleaned and prepared before application of the cement. A dummy gauge was used for temperature compensation; it was permanently bonded onto toroidal transducer made of the same material. The active gauge was bonded on the core that was to be stressed. Both gauges were then connected to the bridge. The internal resistance of the bridge was initially balanced for zero displacement condition to eliminate effect of internal stress on the measurements. Balance of the bridge was represented as zero reading from the bridge. The active transducer core was then mounted onto the displacement application mechanism. Tensile stress was represented as positive reading and compressive stress was represented as negative readings from the bridge.

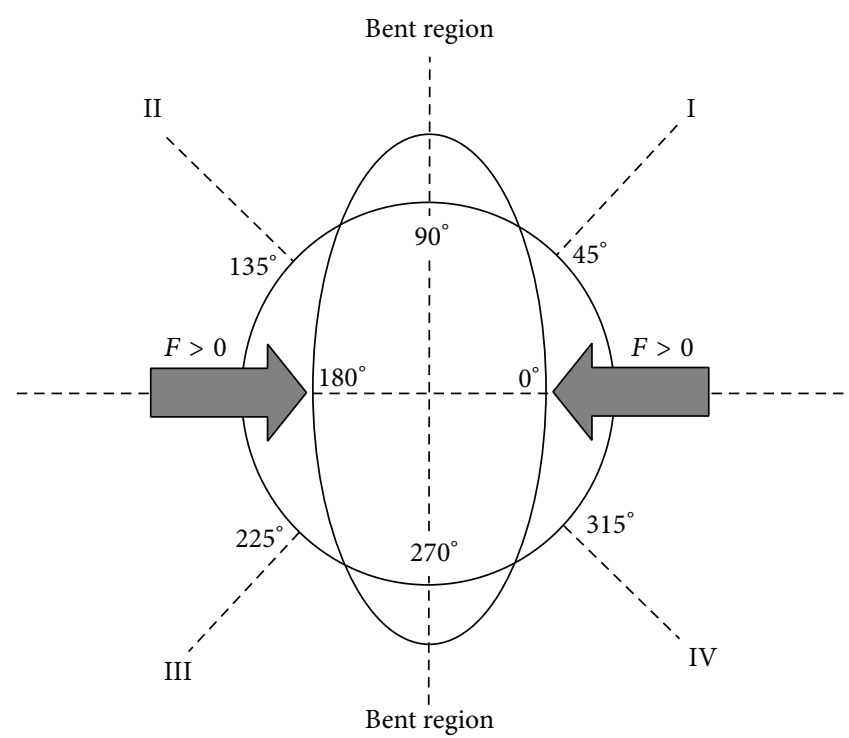

FIGURE 5: Direction of the applied forces and location of the strain gauges and position of the measured stress on toroidal core.

In the first stage of the study, stress measurements were carried out on the inner and the outer surfaces of the Fe base toroidal transducer core. The core was mounted onto the stress application mechanism and the bridge was balanced. Stress measurements were carried out for different displacement conditions. These measurements were carried out for displacement applied at different positions on the toroidal core as shown in Figure 5. The measurements were repeated five times to obtain repeatability and statistical errors of the measurements.

The toroidal core was displaced from 0 to $20 \mathrm{~mm}$ with $\pm 0.5 \mathrm{~mm}$ resolution. The tensile stress induced at the $0^{\circ}$ position of the inner surface of the toroidal core increased with increasing displacement, and the induced stress reached a maximum of approximately $+880 \mathrm{MPa}$ for the maximum displacement condition. However, that induced on the inner surface at the $90^{\circ}$ position was compressive. It was about $-900 \mathrm{MPa}$ for the maximum displacement condition of $20 \mathrm{~mm}$. Meanwhile tensile stress was induced at other positions such as the $20^{\circ}$ and $30^{\circ}$. They reached $+730 \mathrm{MPa}$ and $+300 \mathrm{MPa}$, respectively. The stress was compressive at the $50^{\circ}$ and $70^{\circ}$ positions. These reached $-120 \mathrm{MPa}$ and $-620 \mathrm{MPa}$, respectively, for the $20 \mathrm{~mm}$ displacement condition. Compressive stress occurred at the $110^{\circ}$ and $130^{\circ}$ positions while tensile stress was found to be present at the $150^{\circ}, 160^{\circ}$, and $180^{\circ}$; these had values of $-730 \mathrm{MPa},-55 \mathrm{MPa},+450 \mathrm{MPa}$, $+730 \mathrm{MPa}$, and $+850 \mathrm{MPa}$, respectively. Figure 6 shows the variation of induced stress on the inner surface of the Fe based toroidal core between the $0^{\circ}$ and $90^{\circ}$ positions, and Figure 7 shows the induced stress between the $90^{\circ}$ and $180^{\circ}$ positions on the inner surface of the amorphous toroidal transducer core.

Stress distribution of the second half of the toroidal core between the $180^{\circ}$ and $360^{\circ}$ position was symmetrical to the first half of the core. Although there could be some 


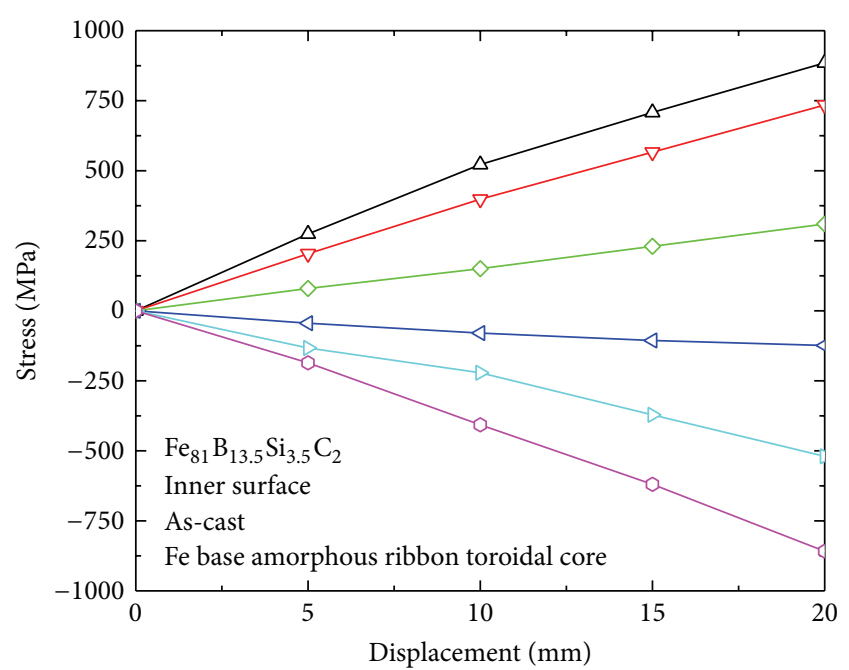

Positions

$\begin{array}{ll}\neg 0^{\circ} & \multimap 50^{\circ} \\ \multimap 20^{\circ} & \multimap 70^{\circ} \\ \multimap 30^{\circ} & \multimap 90^{\circ}\end{array}$

FIGURE 6: Stress distribution on the inner surface of the as-cast, $\mathrm{Fe}$ based, $0.5 \mathrm{~mm}$ thick, and $30 \mathrm{~mm}$ inner diameter amorphous toroidal transducer core for $0^{\circ}, 20^{\circ}, 30^{\circ}, 50^{\circ}, 70^{\circ}$, and $90^{\circ}$ positions.

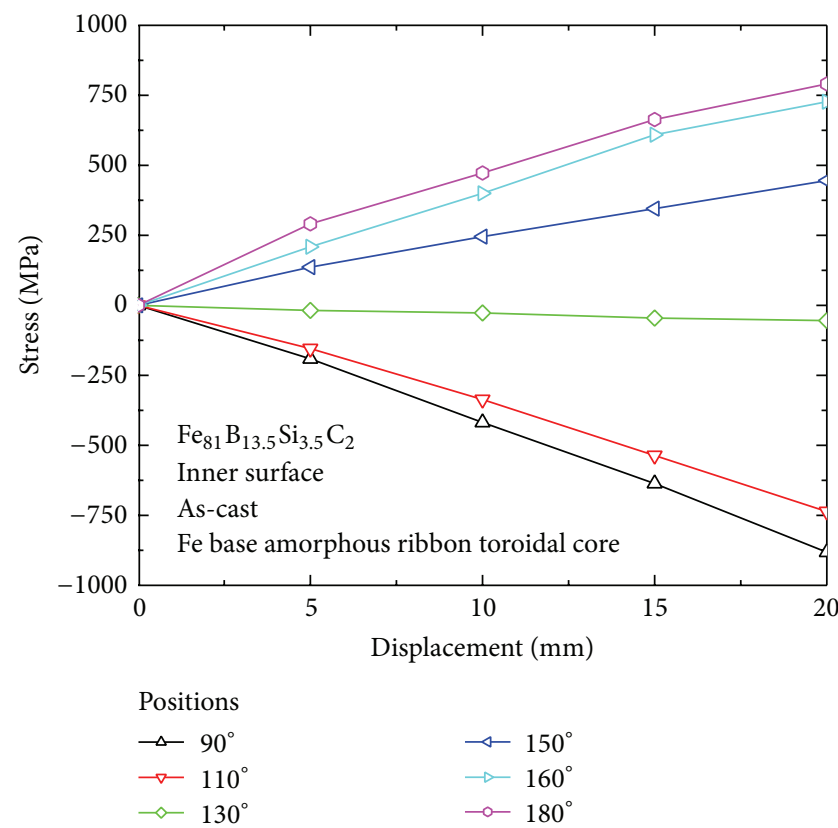

FIgURE 7: Stress distribution on the inner surface of the as-cast, Fe based, $0.5 \mathrm{~mm}$ thick, and $30 \mathrm{~mm}$ inner diameter amorphous toroidal transducer core for $90^{\circ}, 110^{\circ}, 130^{\circ}, 150^{\circ}, 160^{\circ}$, and $180^{\circ}$ positions.

differences in the magnitude of the induced stress, between the two halves, the stress distribution was similar; there were tensile stresses at the $180^{\circ}$ and $360^{\circ}$ positions of approximately $+800 \mathrm{MPa}$, for full displacement of $20 \mathrm{~mm}$.

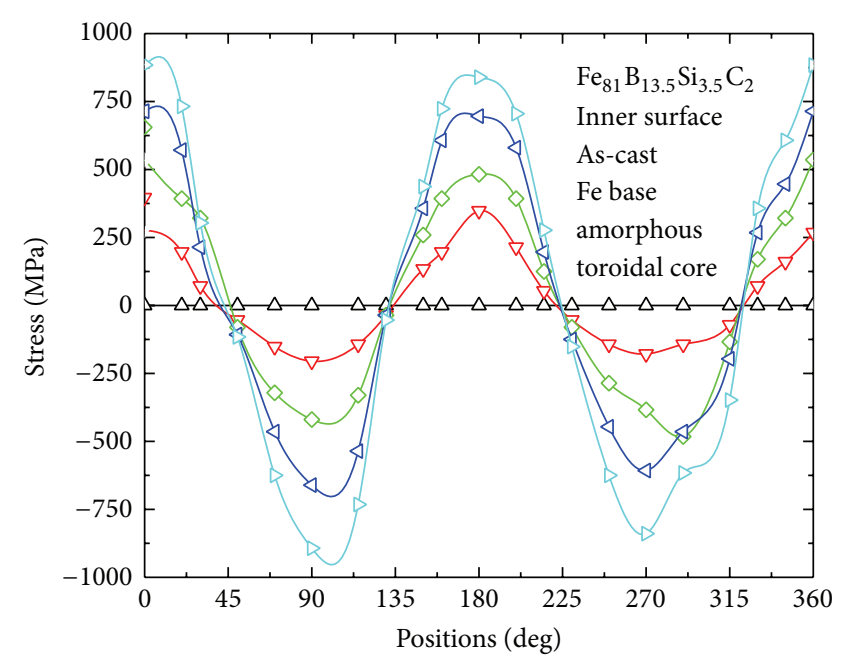

$$
\begin{array}{ll}
\text { Displacements } & \\
\neg-0 \mathrm{~mm} & \smile 15 \mathrm{~mm} \\
\rightarrow-5 \mathrm{~mm} & \longrightarrow 20 \mathrm{~mm} \\
\neg 10 \mathrm{~mm} &
\end{array}
$$

FIGURE 8: Stress distribution on the inner surface, around the circumference of the as-cast, Fe based, $0.5 \mathrm{~mm}$ thick, and $30 \mathrm{~mm}$ inner diameter amorphous toroidal transducer core.

A compressive stress of approximately $-850 \mathrm{MPa}$ occurred at the $270^{\circ}$ position of the inner surface of the toroidal transducer core for maximum displacement. The variation of induced stress against displacement between the $180^{\circ}$ and $360^{\circ}$ positions was similar with stress distribution between $0^{\circ}$ and $180^{\circ}$ positions on the inner surface of the core due to toroidal geometry. The stress variations for all positions on the inner surface of the toroidal transducer core were linear for all displacements.

The induced stress on the outer surface of the amorphous toroidal transducer core was opposite in nature to that of the inner surface. Compressive stress of about $-800 \mathrm{MPa}$ was induced at the $0^{\circ}\left(360^{\circ}\right)$ and $180^{\circ}$ positions. Compressive stress, varying in magnitude and reaching a maximum of about $-600 \mathrm{MPa}$, occurred at the $20^{\circ}, 30^{\circ}, 150^{\circ}, 160^{\circ}, 200^{\circ}$, $210^{\circ}, 330^{\circ}$, and $340^{\circ}$ positions (for full displacement condition). Tensile stress of $+800 \mathrm{MPa}$ appeared at the $90^{\circ}$ and $270^{\circ}$ positions. At the $50^{\circ}, 70^{\circ}, 110^{\circ}, 130^{\circ}, 230^{\circ}, 250^{\circ}, 290^{\circ}$, and $310^{\circ}$ positions, tensile stresses were induced; these varied in magnitude up to a maximum of $+600 \mathrm{MPa}$ for maximum displacement condition.

Figure 8 shows the stress distribution on the inner surface, around the circumference of the amorphous toroidal transducer core.

Figures 9 and 10 show variation of induced stress versus displacement between the $0^{\circ}$ and $360^{\circ}$ positions on the outer surface of amorphous toroidal transducer core. Also it was similar between $180^{\circ}$ and $360^{\circ}$ positions. Variation of the induced stress was linear for each position of outer surface of the core. 


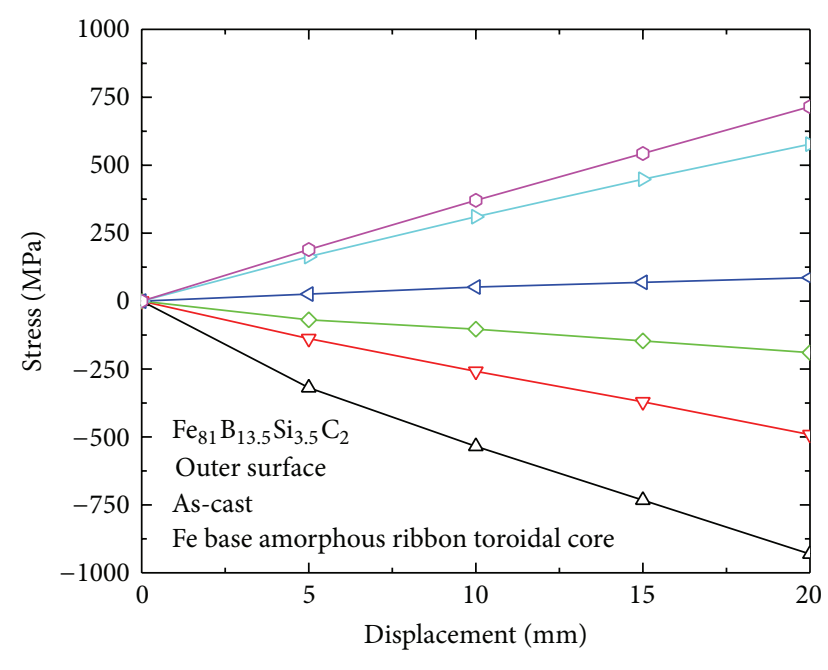

\begin{tabular}{|c|c|}
\hline Positions & \\
\hline$\triangle-0^{\circ}$ & $\triangleleft 50^{\circ}$ \\
\hline$\rightarrow-20^{\circ}$ & $\rightarrow 70$ \\
\hline$\leadsto-30^{\circ}$ & $\rightarrow$ \\
\hline
\end{tabular}

Figure 9: Stress distribution on the outer surface of the as-cast, Fe based, $0.5 \mathrm{~mm}$ thick, and $30 \mathrm{~mm}$ inner diameter amorphous toroidal transducer core for $0^{\circ}, 20^{\circ}, 30^{\circ}, 50^{\circ}, 70^{\circ}$, and $90^{\circ}$ positions.

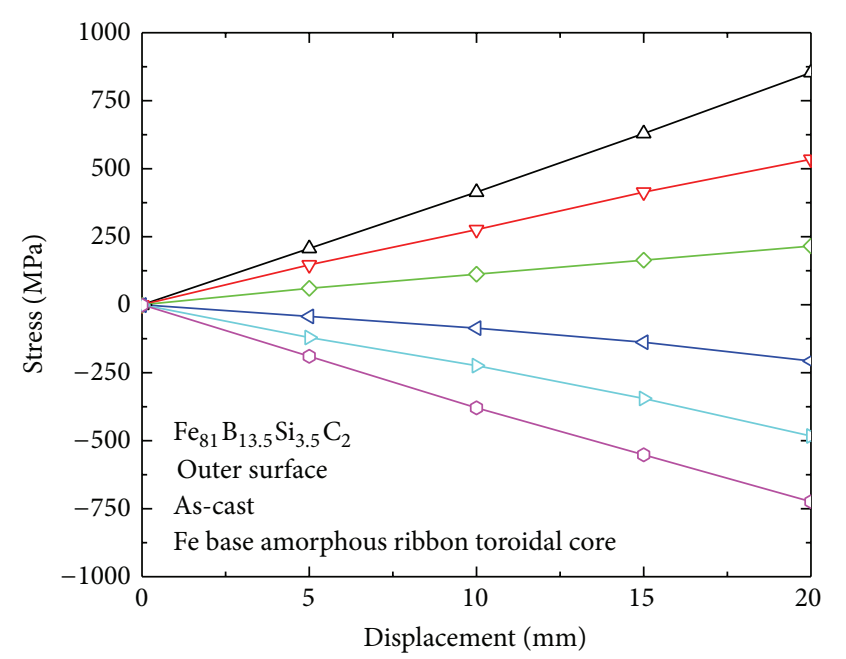

$$
\begin{array}{ll}
\text { Positions } & \\
\neg-90^{\circ} & \multimap 150^{\circ} \\
\multimap-110^{\circ} & \rightarrow 160^{\circ} \\
\multimap-130^{\circ} & \multimap-180^{\circ}
\end{array}
$$

FIGURE 10: Stress distribution on the outer surface of the as-cast, Fe based, $0.5 \mathrm{~mm}$ thick, and $30 \mathrm{~mm}$ inner diameter amorphous toroidal transducer core for $90^{\circ}, 110^{\circ}, 130^{\circ}, 150^{\circ}, 160^{\circ}$, and $180^{\circ}$ positions.

Figure 11 shows the stress distribution on the outer surface of the core. A nonuniform stress distribution around the circumference of the toroidal core was obtained for both the inner and outer surfaces of the core. In both cases, stress reached a zero value at particular regions such as the $45^{\circ}, 135^{\circ}$, $225^{\circ}$, and $315^{\circ}$ positions.
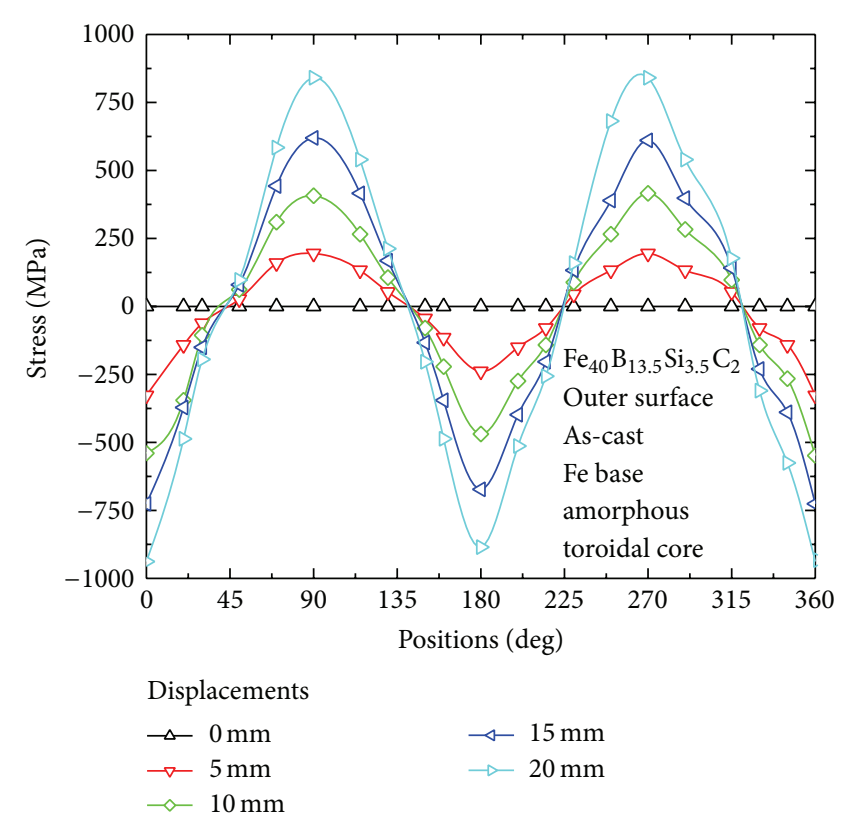

Figure 11: Stress distribution on the outer surface, around the circumference of the as-cast, Fe based, $0.5 \mathrm{~mm}$ thick, and $30 \mathrm{~mm}$ inner diameter amorphous toroidal transducer core.

This implies that the stress distribution around the circumference of the core is nonlinear in nature. For both surfaces, there existed regions incurring the three possible stress conditions, that is, tensile, compressive, and stress free. This gives a warning to us about the construction of the amorphous toroidal transducers; the search and magnetisation coils should be located around particular regions, such as the maximum bending regions and the $90^{\circ}$ and $270^{\circ}$ positions for the maximum stress sensitivity as given in Figure 12.

\section{Conclusion}

In conclusion, the induced stress increased linearly with increasing displacement. Characteristics of the induced stresses on the inner and outer surfaces of the toroidal transducer cores were opposite in nature, that is, tensile and compressive stresses. Amorphous toroidal core reacts as elastic spring for applied displacement.

There was a phase transition from tensile to compressive or vice versa at particular regions such as the $45^{\circ}, 135^{\circ}, 225^{\circ}$, and $315^{\circ}$ positions. Induced stress on the inner and outer surfaces of the toroidal transducer cores was related most significantly to the thickness of the toroidal core rather than the thickness of the amorphous ribbon, for the multiwrap configuration.

Nonlinear stress distribution occurred around the circumference of the inner and outer surfaces of amorphous toroidal transducer cores. However, variations of the localised stresses with increasing displacement were linear.

When the toroidal core was displaced along the $0^{\circ}$ and $180^{\circ}$ positions, maximum stress occurred at the bent regions 


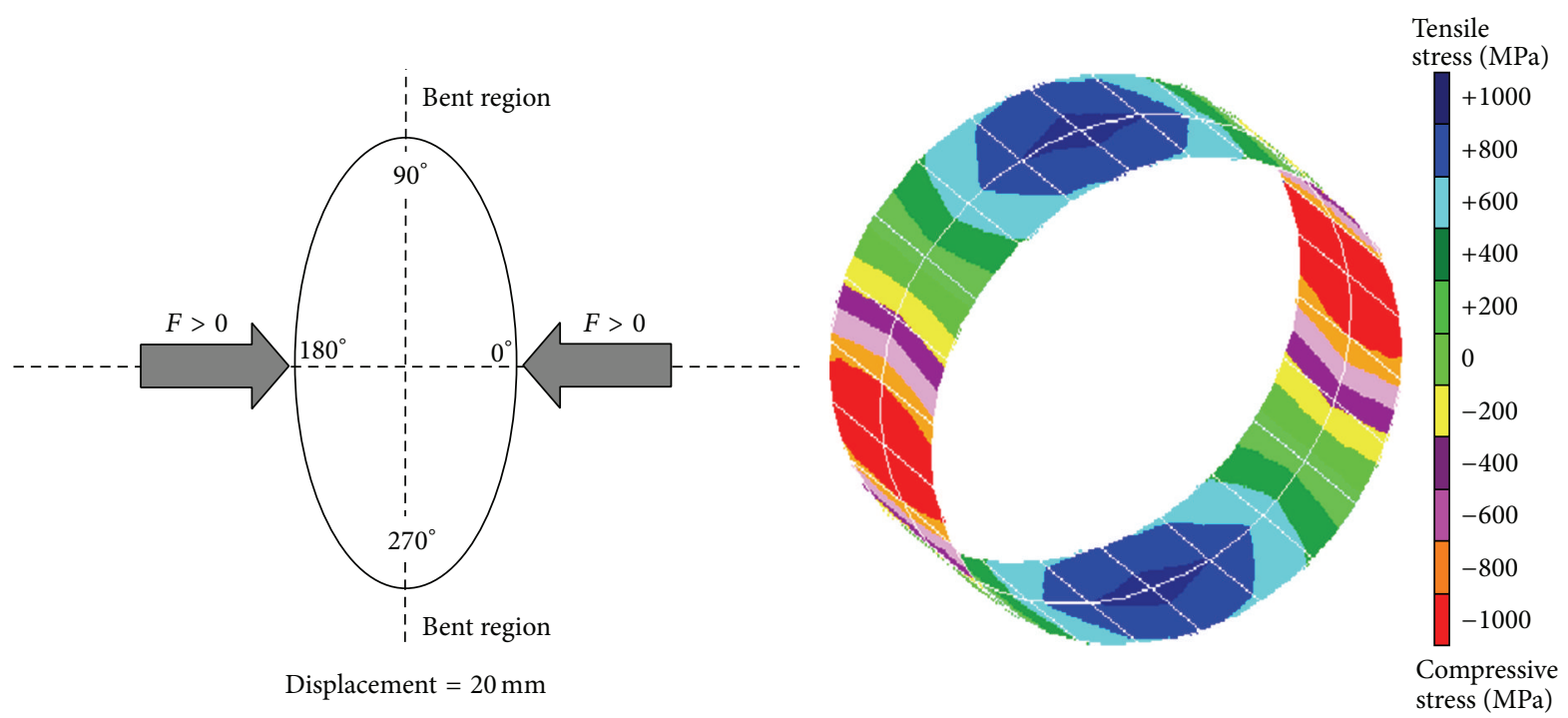

FIGURE 12: Stress distributions on the outer surface of the $0.5 \mathrm{~mm}$ thick amorphous ribbon toroidal transducer core at $20 \mathrm{~mm}$ displacement condition.

of $90^{\circ}$ and $270^{\circ}$ positions. Because of this, these regions are very important for toroidal transducer applications, especially in terms of locating the magnetisation and search windings.

\section{Conflict of Interests}

The author declares that there is no conflict of interests regarding the publication of this paper.

\section{References}

[1] K. J. Overshott, "Physical principles," in Sensors, A Comprehensive Survey-vol. 5, Magnetic Sensors, K. J. Overshott and R. Boll, Eds., pp. 33-42, VCH Verlagsgesellschaft mbH, Veinheim, Germany, 1989.

[2] T. Meydan, Transducer using amorphous ribbon materials [Ph.D. thesis], Wolfson Centre, UCC, University of Wales, Cardiff, UK, 1984.

[3] G. Hinz and H. Voigt, "Magnetoelastic sensors," in Sensors, A Comprehensive Survey - vol. 5, Magnetic Sensors, K. J. Overshott and R. Boll, Eds., pp. 97-152, VCH Verlagsgesellschaft mbH, Veinheim, Germany, 1989.

[4] K. Mohri and S. Korekoda, "New force transducers using amorphous ribbon cores," IEEE Transactions on Magnetics, vol. 14, no. 5, pp. 1071-1075, 1978.

[5] K. Mohri and E. Sudoh, "Sensitive force transducers using a single amorphous core multivibrator bridge," IEEE Transactions on Magnetics, vol. 15, no. 6, pp. 1806-1808, 1979.

[6] K. Mohri and E. Sudoh, "New extensometers using amorphous magnetostrictive ribbon wound cores," IEEE Transactions on Magnetics, vol. 17, no. 3, pp. 1317-1319, 1981.

[7] K. Mohri and S. Korekoda, "New force transducers using amorphous ribbon cores," IEEE Transactions on Magnetics, vol. 14, no. 5, pp. 1071-1075, 1978.
[8] T. Meydan and K. J. Overshott, "Amorphous force transducers in ac applications," Journal of Applied Physics, vol. 53, no. 11, pp. 8383-8385, 1982.

[9] M. G. Blundell, T. Meydan, and K. J. Overshott, "An ac force transducer using amorphous ribbon cores," Journal of Magnetism and Magnetic Materials, vol. 26, no. 1-3, pp. 161-164, 1982.

[10] T. Meydan and K. J. Overshott, "Amorphous ribbon transducers," Journal of Magnetism and Magnetic Materials, vol. 41, no. 1-3, pp. 449-451, 1983.

[11] T. Meydan, M. Göktepe, A. Honda, and N. Derebasi, "Influence of bending stress on domain motion in amorphous material based magneto-elastic transducers," Journal of Magnetism and Magnetic Materials, vol. 112, no. 1-3, pp. 269-271, 1992.

[12] M. Göktepe and T. Meydan, "Influence of bending stress on flux distribution in toroidal transducers," Journal of Magnetism and Magnetic Materials, vol. 133, no. 1-3, pp. 550-552, 1994.

[13] C. C. Perry and H. R. Linssner, The Strain Gage Prime, McGrawHill Book Co., 2nd edition, 1962.

[14] RS Components Ltd, "Strain gauges and load cells," RS Data Library, vol. 8155, pp. 1-3, 1987.

[15] RS Components Ltd, "Strain gauges and amplifier," RS Data Library, vol. 3655, pp. 1-5, 1987.

[16] Philips, Manual For PR9307 Carrier Frequency Strain Gauge Bridge, Philips, UK. 

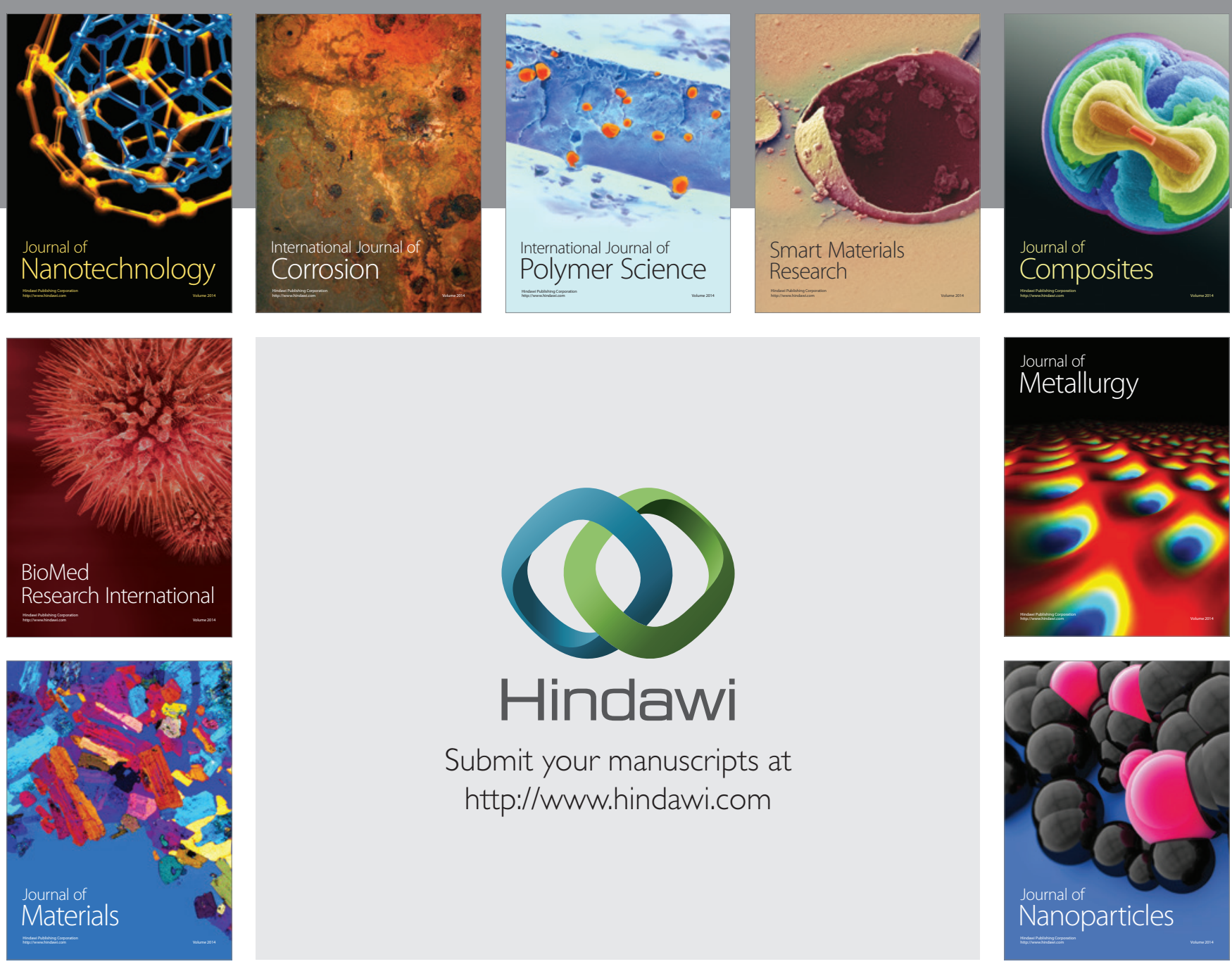

Submit your manuscripts at http://www.hindawi.com
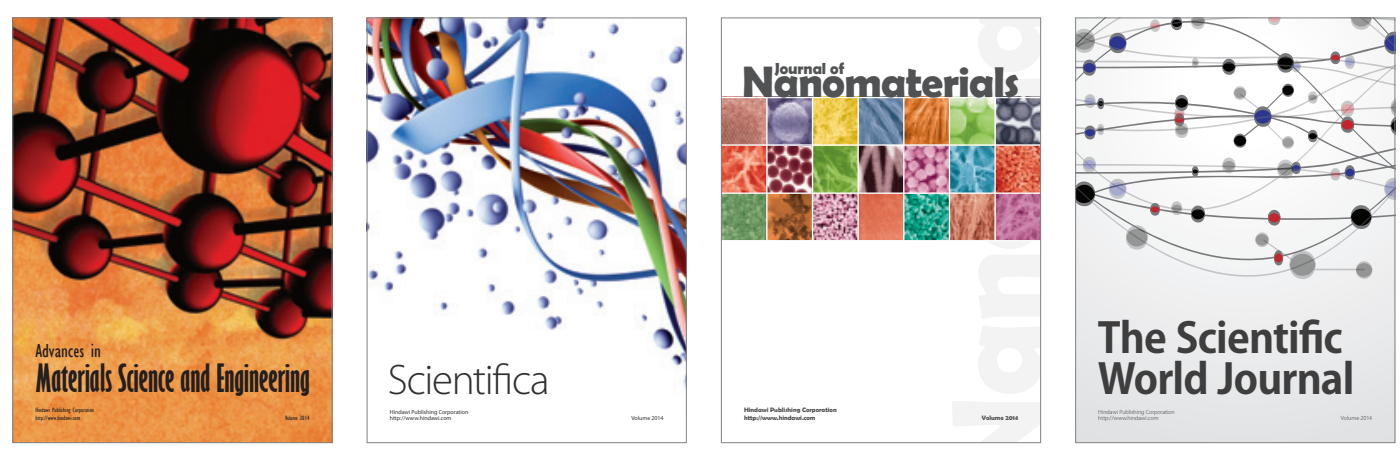

\section{The Scientific World Journal}
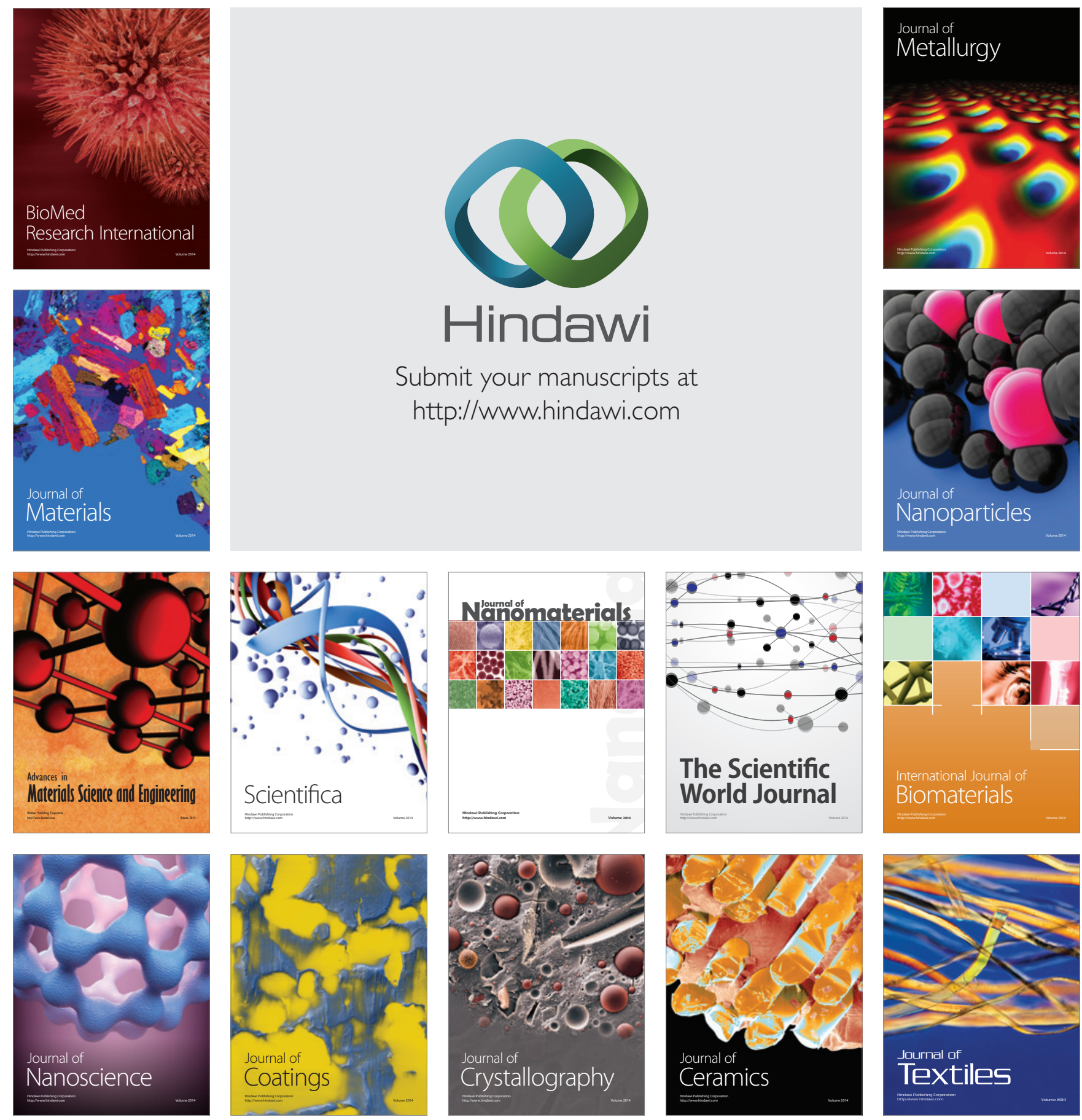